\title{
Time to Prescribe Dual instead of Mono
}

\author{
Joon Young Choi, M.D.
}

Division of Pulmonary and Critical Care Medicine, Department of Internal Medicine, Incheon St. Mary's Hospital, College of Medicine, The Catholic University of Korea, Incheon, Republic of Korea

Chronic obstructive pulmonary disease (COPD) is one of the most common diseases with profound morbidity and mortality $^{1}$. Inhaled long-acting bronchodilators are the cornerstones of treatment; these not only control symptoms but also prevent exacerbation events and attenuate the decline in lung function ${ }^{2}$. Historically, tiotropium (TIO) was the first approved long-acting muscarinic antagonist (LAMA), and was one of the most commonly used inhalers in COPD patients, past decades ${ }^{3}$. Recent reports revealed that newly developed long-acting $\beta 2$-agonist (LABA)/LAMA combinations showed superior outcomes compared with monobronchodilators and inhaled corticosteroid/LABA combination in terms of symptom control, attenuation of lung function decline and exacerbation $^{3}$. Regarding these results, analyses of clinical outcomes in switching from a monobronchodilator to dual bronchodilators may give us some clues in treating COPD patients who have formerly used monobronchodilators.

Lee et al. ${ }^{4}$ performed a 12-week, randomized, parallel group trial on patients with mild to moderate COPD who formerly used TIO. After randomization to indacaterol/glycopyrronium (IND/GLY) and TIO groups, the former group immediately changed their medication and the TIO group did not. After 12 weeks of their challenge, the clinical outcomes (including the pre-dose trough forced expiratory volume in 1 second $\left[\mathrm{FEV}_{1}\right]$, the transition dyspnea index [TDI] focal score, the COPD assessment test [CAT] total score and rescue medication use) were analyzed. The change in pre-dose trough $\mathrm{FEV}_{1}$ (the

Address for correspondence: Joon Young Choi, M.D.

Division of Pulmonary and Critical Care Medicine, Department of Internal Medicine, Incheon St. Mary's Hospital, College of Medicine, The Catholic University of Korea, 56 Dongsu-ro, Bupyeong-gu, Incheon 21431, Republic of Korea

Phone: 82-32-280-5749, Fax: 82-32-280-5748

E-mail: tawoe@naver.com

Received: Feb. 15, 2021

Revised: Mar. 3, 2021

Accepted: Mar. 10, 2021

Published online: Mar. 10, 2021

(c) It is identical to the Creative Commons Attribution Non-Commercial License (http://creativecommons.org/licenses/by-nc/4.0/). primary outcome) showed significantly superior in the IND/ GLY group compared to TIO group (least square mean treatment difference $[\Delta] 50 \mathrm{~mL} ; \mathrm{p}=0.01$ ). The changes in the TDI focal scores, CAT total scores, and rescue medication use did not differ between the groups but tended to be better in IND/ GLY group. Safety index showed comparable between the two groups.

The Canadian real-world POWER study was similar to that of Lee et al. ${ }^{4,5}$. The trough $\mathrm{FEV}_{1}$ improved by $176 \mathrm{~mL}$ by week 16 after switching from TIO to IND/GLY $(70 \mathrm{~mL}$, in Lee et al. ${ }^{4}$ ), and the mean TDI total scores and CAT scores also significantly improved. The safety profiles of the two groups were comparable. The CRYSTAL study, which was a multicenter randomized controlled study that investigate efficacy of direct switching to IND/GLY in moderate COPD patients, revealed more favorable outcomes in an IND/GLY group than in a monobronchodilator continuation group in terms of the trough $\mathrm{FEV}_{1}(\Delta, 101 \mathrm{~mL})$ and TDI score $(\Delta, 1.26)^{6}$. Moreover, recent pooled analyses of the SHINE ${ }^{7}, \mathrm{SPARK}^{8}$, and $\mathrm{ARISE}^{9}$ trial data enrolling long-acting bronchodilator-naïve moderateto-very severe COPD patients presented greater improvement in trough $\mathrm{FEV}_{1}$ in an IND/GLY compared to a TIO group $(\Delta$, $86 \mathrm{~mL}$ ), in line with study of Lee et al, ${ }^{4,10}$.

These diverse studies of different study designs correspondingly support use of IND/GLY rather than TIO in previous TIO users and bronchodilator-naïve patients in COPD patients. However, the Global Initiative for Chronic Obstructive Lung Disease (GOLD) 2020 guideline recommends initial use of monobronchodilator for groups B and C, and permits such usage in group D patients ${ }^{11}$. As the study of Lee et al. ${ }^{4}$ also includes mild COPD patients, the results may imply necessity of dual bronchodilators in their earlier course of the disease. The pharmacological effects of switching from TIO to IND/GLY in various GOLD subgroups have not been investigated; subgroup analyses may be important when choosing an optimal initial therapy.

\section{Conflicts of Interest}

No potential conflict of interest relevant to this article was reported. 


\section{References}

1. Lopez-Campos JL, Tan W, Soriano JB. Global burden of COPD. Respirology 2016;21:14-23.

2. Wedzicha JA, Banerji D, Chapman KR, Vestbo J, Roche N, Ayers RT, et al. Indacaterol-glycopyrronium versus salmeterol-fluticasone for COPD. N Engl J Med 2016;374:2222-34.

3. Rhee CK, Yoshisue H, Lad R. Fixed-dose combinations of long-acting bronchodilators for the management of COPD: global and Asian perspectives. Adv Ther 2019;36:495-519.

4. Lee SH, Rhee CK, Yoo K, Park JW, Yong SJ, Kim J, et al. Direct switch from tiotropium to indacaterol/glycopyrronium in chronic obstructive pulmonary disease patients in Korea. Tuberc Respir Dis 2021;84:96-104.

5. Kaplan A, Chapman KR, Anees SM, Mayers I, Rochdi D, Djandji M, et al. Real-life effectiveness of indacaterol-glycopyrronium after switching from tiotropium or salmeterol/ fluticasone therapy in patients with symptomatic COPD: the POWER study. Int J Chron Obstruct Pulmon Dis 2019;14:24960.

6. Vogelmeier CF, Gaga M, Aalamian-Mattheis M, Greulich T, Marin JM, Castellani W, et al. Efficacy and safety of direct switch to indacaterol/glycopyrronium in patients with moderate COPD: the CRYSTAL open-label randomised trial.
Respir Res 2017;18:140.

7. Bateman ED, Ferguson GT, Barnes N, Gallagher N, Green Y, Henley M, et al. Dual bronchodilation with QVA149 versus single bronchodilator therapy: the SHINE study. Eur Respir J 2013;42:1484-94.

8. Wedzicha JA, Decramer M, Ficker JH, Niewoehner DE, Sandstrom T, Taylor AF, et al. Analysis of chronic obstructive pulmonary disease exacerbations with the dual bronchodilator QVA149 compared with glycopyrronium and tiotropium (SPARK): a randomised, double-blind, parallel-group study. Lancet Respir Med 2013;1:199-209.

9. Asai K, Hirata K, Hashimoto S, Fukuchi Y, Kitawaki T, Ikeda $\mathrm{K}$, et al. Efficacy and safety of indacaterol/glycopyrronium in Japanese patients with COPD: pooled analysis of SHINE and ARISE. Respir Investig 2016;54:428-35.

10. Muro S, Yoshisue H, Kostikas K, Olsson P, Gupta P, Wedzicha JA. Indacaterol/glycopyrronium versus tiotropium or glycopyrronium in long-acting bronchodilator-naive COPD patients: a pooled analysis. Respirology 2020;25:393-400.

11. 2020 Global strategy for prevention, diagnosis and managment of COPD [Internet]. Fontana, WI: Global Initiative for Chronic Obstructive Lung Disease; 2020 [cited 2020 Dec 10]. Available from: https://goldcopd.org/gold-reports/. 